\title{
Behavioral Research
}

National Cancer Institute

\section{Source}

National Cancer Institute. Behavioral Research. NCI Thesaurus. Code C15185.

Studies of the motivating factors that influence health practices as well as efforts to modify these practices. 